www.jmscr.igmpublication.org Impact Factor 5.244

Index Copernicus Value: 83.27 ISSN (e)-2347-176x ISSN (p) 2455-0450 crossref DOI:_http://dx.doi.org/10.18535/jmscr/v4i8.53

\title{
Evaluation of Dental Caries Awareness among the Parents of School Going Children
}

Author

Shanmuga Priya.S ${ }^{1}$, Dr Mahesh ${ }^{2}$

${ }^{1}$ Undergraduate BDS

${ }^{2}$ Saveetha Dental College and Hospital

Corresponding author

Dr Mahesh

Dent of Pedodontics, Saveetha Dental College and Hospital

\section{ABSTRACT}

AIM: The purpose of this study is to evaluate the awareness of parents about the dental caries among the school going children in chennai.

OBJECTIVES: The objective of this study is to investigate the dental caries awareness in the different medium school children by questionnaire method.

BACKGROUND: The dental caries is one of the most common infectious diseases all over the world. Overall dental caries is more severe in the baby teeth of 4-11 years children than the permanent tooth. However, an active effort of the school authority and dental health care team can make a awareness program more effective and also make a parents more aware

about the dental caries prevention and milk tooth preservation.

MATERIALS AND METHODS: Total 80 parents from different socioeconomic groups participated in the study. Data were collected using a self-administered questionnaire addressing various aspects of knowledge and attitude of parents toward oral health and treatment modalities

Awareness among parents was significantly lower in low socioeconomic group. Their attitude toward dental treatment differed significantly in high socioeconomic group preferred going to the pediatric dentist.

CONCLUSION: The level of awareness among parents is relatively low and there is need for the implementation of oral health awareness programs for parents to change their attitude toward dental treatment of their children

KEY WORDS: dental caries, oral health program, school children's.

\section{INTRODUCTION}

Dental caries is a ecological disease in which the diet, the host and microbial flora interact over a period of time so as to encourage the demineralisation of tooth enamel with resultant caries formation ${ }^{(1)}$. Untreated oral disease frequently leads to serious general health problem. Due to mechanical life, people are neglecting the oral health. It is necessary to create awareness about dental caries and oral hygiene ${ }^{(2)}$. As oral diseases are largely preventable, it is hoped that with early exposure to oral health care activities, the prevalence of dental diseases will be reduced in children and they would be more receptive to dental service ${ }^{(3)}$. The aim of this study is to evaluate the awareness of dental caries among the parents of school going children. 


\section{MATERIALS AND METHODS}

A total of 80 parents participated in the study who visited to the department of pediatric and preventive dentistry in Saveetha dental college and hospital. They were made to fill a multiple choice questionnaire, specifically related to their awareness regarding deciduous dentition.

The first part of questionnaire included demographic information regarding parents gender, child age and socioeconomic status. The second part of question is to describe parents beliefs, attitudes, behaviour towards their children's oral health, indicating different risk for dental diseases among children. The modalities divided into 2 groups according to their socioeconomic status.

Group 1: parents having their annual income below 20,000

Group 2: parents having their annual income above 20,000

\section{RESULTS}

Table 1: Attitudes towards professional dental care among the study population

\begin{tabular}{|c|c|c|c|c|}
\hline & Frequency & Percentage $(\%)$ & Frequency & Percentage $(\%)$ \\
\hline & Group I & & Group II & \\
\hline \multicolumn{5}{|c|}{ How often do you visit the dentist } \\
\hline A)Regularly & 8 & $10 \%$ & 16 & $20 \%$ \\
\hline B)when in pain & 17 & $21.25 \%$ & 21 & $26.25 \%$ \\
\hline C)occasionally & 7 & $8.75 \%$ & 11 & $13.75 \%$ \\
\hline \multicolumn{5}{|c|}{ Are regular visits to dentist necessary } \\
\hline A)yes & 19 & $23.75 \%$ & 32 & $40 \%$ \\
\hline B)no & 6 & $7.5 \%$ & 12 & $15 \%$ \\
\hline C)don't known & 7 & $8.75 \%$ & 4 & $5 \%$ \\
\hline \multicolumn{5}{|c|}{ Driving factor for your last visit } \\
\hline A)tooth ache & 25 & 31.25 & 30 & $37.5 \%$ \\
\hline B)parents advice & 4 & $5 \%$ & 7 & $8.75 \%$ \\
\hline C)dentist advice & 2 & $2.5 \%$ & 8 & $10 \%$ \\
\hline D) other reasons & 1 & $1.25 \%$ & 3 & $3.75 \%$ \\
\hline \multicolumn{5}{|c|}{ Reasons behind not visiting the dentist } \\
\hline A)fear & 22 & $27.5 \%$ & 34 & $42.5 \%$ \\
\hline B)of drilling & 1 & $1.25 \%$ & 3 & $3.75 \%$ \\
\hline C)of needle & 3 & $3.75 \%$ & 7 & $8.75 \%$ \\
\hline D)hight cost & 6 & $7.5 \%$ & 1 & $1.25 \%$ \\
\hline
\end{tabular}

\section{Dentist explain the procedures before} treatment

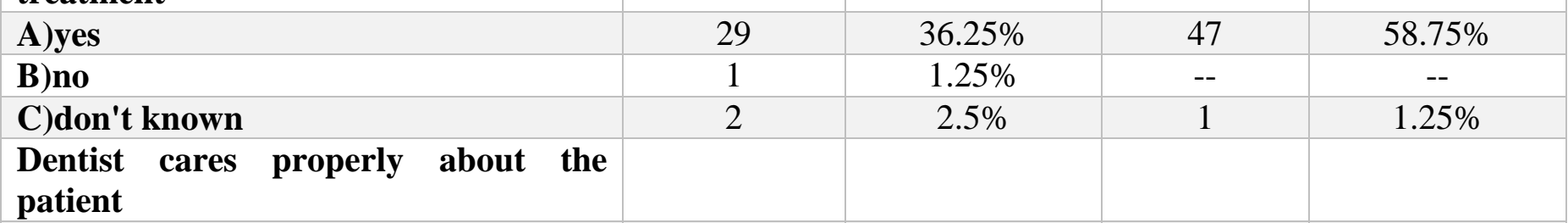

\begin{tabular}{|l|c|c|c|c|}
\hline A)yes & 31 & $38.75 \%$ & 45 & $56.25 \%$ \\
\hline B)no & 1 & $1.25 \%$ & 1 & $1.25 \%$ \\
\hline C)don't known & -- & -- & 2 & $2.5 \%$ \\
\hline Does caries affects the dental aesthetics & & & & \\
\hline A)yes & 26 & $32.5 \%$ & 39 & $48.75 \%$ \\
\hline B)no & 5 & $6.25 \%$ & 3 & $3.75 \%$ \\
\hline C)don't known & 1 & $1.25 \%$ & 6 & $7.5 \%$ \\
\hline Do sweets affects dental health & & & & \\
\hline A)yes & 24 & $30 \%$ & 42 & $58.75 \%$ \\
\hline \hline
\end{tabular}




\begin{tabular}{|l|c|c|c|c|}
\hline B)no & 3 & $3.75 \%$ & 2 & $2.5 \%$ \\
\hline C)don't known & 5 & $6.25 \%$ & 4 & $5 \%$ \\
\hline Do soft drinks affects dental health & & & & \\
\hline A)yes & 21 & $26.25 \%$ & 33 & $41.25 \%$ \\
\hline B)no & 8 & $10 \%$ & 9 & $11.25 \%$ \\
\hline C)don't known & 3 & $3.75 \%$ & 6 & $7.5 \%$ \\
\hline $\begin{array}{l}\text { Does the health of mouth and dentition } \\
\text { impact the health of body }\end{array}$ & & & & \\
\hline A)yes & 23 & $28.75 \%$ & 39 & $48.75 \%$ \\
\hline B)no & 6 & $7.5 \%$ & 4 & $5 \%$ \\
\hline C)don't known & 3 & $3.75 \%$ & 5 & $6.25 \%$ \\
\hline
\end{tabular}

Table 2: Oral health habits among the study population

Oral hygiene methods used

\begin{tabular}{|c|c|c|c|}
\hline Frequency & Percentage(\%) & Frequency & Percentage(\%) \\
Group I & & Group II & \\
\hline
\end{tabular}

\begin{tabular}{|c|c|c|c|c|}
\hline A)tooth brush and paste & 31 & $38.75 \%$ & 45 & $56.25 \%$ \\
\hline B)dental floss & -- & -- & -- & -- \\
\hline C)mouth wash & 1 & $1.25 \%$ & 3 & $3.75 \%$ \\
\hline D)tooth picks & -- & -- & -- & -- \\
\hline \multicolumn{5}{|l|}{ Methods of brushing used } \\
\hline A)circular & 26 & $32.5 \%$ & 38 & $47.5 \%$ \\
\hline B)horizontal & 4 & $5 \%$ & 3 & $3.75 \%$ \\
\hline C)vertical & 2 & $2.5 \%$ & 7 & $8.75 \%$ \\
\hline \multicolumn{5}{|l|}{ Frequency of brushing } \\
\hline A)less than once & -- & -- & -- & -- \\
\hline B)once & 17 & $21.25 \%$ & 19 & $23.75 \%$ \\
\hline C)twice & 15 & $18.75 \%$ & 29 & $36.25 \%$ \\
\hline \multicolumn{5}{|l|}{$\begin{array}{l}\text { Frequency of changing tooth } \\
\text { brush. }\end{array}$} \\
\hline A)monthly & -- & -- & 2 & $2.5 \%$ \\
\hline B)3monthly & 4 & $5 \%$ & 16 & $20 \%$ \\
\hline C)6monthly & 28 & $35 \%$ & 30 & $37.5 \%$ \\
\hline \multicolumn{5}{|l|}{$\begin{array}{l}\text { Role of parents in supervision } \\
\text { of oral hygiene }\end{array}$} \\
\hline A)parents watch and advice & 11 & $13.75 \%$ & 23 & $28.75 \%$ \\
\hline $\begin{array}{l}\text { B)parents advice only but don't } \\
\text { watch }\end{array}$ & 19 & $23.75 \%$ & 25 & $31.25 \%$ \\
\hline C)parents never cared & 2 & $2.5 \%$ & -- & -- \\
\hline
\end{tabular}

The results revealed that the awareness among parents from group I was low compared to parents from group II (table-1). Significant difference was noted about the knowledge regarding oral health habits among the population (table-2)

Total of 80 parents are participated in this study. Most of them (70\%) reported the toothache was the driving factored or their last visit. $40 \%$ of subjects only examination and routine heck up on their last visit.
The most common cause of not visiting e dentist was fear $(69 \%)$, for needle(13\%), for drilling (5\%) and high cost (9\%). Approximately $80 \%$ were aware that carious teeth and dental caries affect dental aesthetics.

Awareness of importance of tooth brushing for caries prevention was high $(90 \%)$ among the study population. 


\section{DISCUSSION}

Rationale of oral health awareness program is to improve and motivate the parents regarding their dental health and treatment needs. This study highlight that to initiate dental awareness program among people at low socioeconomic groups. ${ }^{(4)}$ Children from low income and disadvantaged families have a disproportionately higher prevalence of untreated dental caries and lower dental care utilisation than higher income group children. A reduction of oral health disparities requires comprehensives oral health promotion strategy for better oral health among low income group children. This strategy include oral health program preventive and comprehensive dental care, social and organisational intervention to multiple barrier to access and utilise dental care ${ }^{(5)}$ American Academy of Pediatric Dentistry recommends cleaning children's teeth as soon as they erupt and use of dental floss when adjacent tooth are touching ${ }^{(6)}$. Many parents in this study from low socioeconomic group did not have the Reception of cleaning their children's teeth using oral hygiene aids, theirs is a need for awareness program's especially in low socioeconomic groups.

It is generally assumes that well educated person is more aware of overall health, but lack of awareness regarding importance of deciduous tooth was evident ${ }^{(7)}$. Attainment of good oral health us based on awareness of good dietary habits and oral hygiene practice. Need for making aware of brushing methods and importance of preventive measures for children via school dental program have been reported in literature( 8$)$

\section{CONCLUSION}

Level of oral health awareness and initiation for dental visits in patients is low. Significant role of pedodontists in organising dental health awareness program for parents and needs to create more awareness about knowledge and importance of first dental visit among society. This study also emphasises the need to initiate positive attitude toward treatment modalities for primary teeth.

\section{REFERENCES}

1. Grover S, Anuradha P. Prevalence and treatment needs of dental caries among 12 and 15 years old school going children in Lucknow city. J Indian Assoc Public Health Dent. 2011;18:105-11.

2. Ganesh SA, Bhatt PK, Jyothi SD. Initial impact of health education program on oral health, knowledge and awareness among 15 year old children of Government High School, Sarakki, Bangalore. J Indian Assoc Public Health Dent. 2007;10:57-65.

3. Othman WM. Guidelines on oral health care for pre- school children . Oral Heath division, ministry of health Malaysia. 2003.

4. Kaur B. Evaluation of oral health awareness in parents of pre- school children. Indian J. Dent Res 2009;20:463-5

5. Kelly SE, Binkley CJ, Neace WP, Gal BS. Barriers to care- seeking for children's oral health among low income caregivers. Am J Public Health 2005;95:1345-51.

6. Wong D, Perez- Spiess S, Julliard K. Attitudes of Chinese parents towards the oral Health of their children with caries. A qualitative study Pediatr Dent 2005;27:505-12.

7. Mani SA, Aziz AA, John J, Ismail NM Knowledge , attitude and practices of oral health Promoting their factors among caretakers of children attending day care centres in Kubang Kerian Malaysia. A preliminary study. J Indian Soc Pedod Prev Dent 2010;28:78-83.

8. Sohn W. Taichman LS, Ismail AI, Reisine S. Caregivers perception of child's oral health Status among low income African American Pediatr Dent 2008;30:480-7. 